\section{Observations on nudging cells in culture}

CELL behaviour has been studied widely in tissue culture, and in many cases individual cells have been shown to inhibit the locomotion of cells with which they make contact ${ }^{1}$. In the embryo, however, cells move mainly in sheets ${ }^{2}$ or streams ${ }^{3-5}$ and in the latter case their locomotion does not appear to be contact inhibited ${ }^{6}$. The question, then, is how the behaviour of individual cells is coordinated in these organised morphogenetic movements. While studying isolated deep cells of the fish, Fundulus heteroclitus, we have made some observations which relate to this question.

Deep cells of blastulae form hemispherical bulges of the cell surface called blebs. As cell locomotion begins during gastrulation some blebs extend to form lobopodia or flatten to form lamellipodia ${ }^{6}$. In films of deep cells blebbing within the embryo it is often difficult to determine whether cells are in contact, and if so, to what extent. Fortunately, however, deep cells isolated from blastulae in culture behave in the same way as cells in the embryo?.

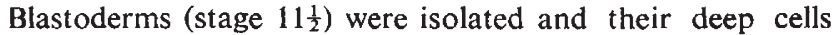
were disaggregated mechanically by flushing through a narrowbore micropipette. This resulted in a suspension of single cells and small clusters which was placed in a deep watch glass containing a simple culture medium ${ }^{8}$. Most of the cells stuck to the glass substratum within $15 \mathrm{~min}$, although they did not flatten but rather adhered over a small portion of the cell surface as in vivo in the blastula. This may have been due to the lesser deformability of cells at this stage ${ }^{9}$. They resumed blebbing during this time. A bulge formed which expanded into a bleb in about 5-8 s. Blebs seemed to be laterally restricted and only involved a small area of the cell surface. Such a bleb was eventually resorbed into the cell and after a variable time another bleb formed almost diametrically opposite the position of the first. The positioning did not seem to be random, in contrast to amphibian gastrula cells ${ }^{10}$. In no instance, in observations of more than 50 cells, has a bleb resorbed and a new bleb formed in the same position.

Most blastula cells in culture initiated new blebs every $30 \mathrm{~s}$. To see if cells in contact influenced each others' blebbing, two attached blastula cells were observed. Both were $40 \mu \mathrm{m}$ in diameter and had a broad contact between them so that each cell was fiattened along the contact. These cells were observed every $15 \mathrm{~s}$ for $5 \mathrm{~min}$ and $70 \%$ of the time they were both blebbing or not blebbing. Many observations of non-contacting deep cells would be required to substantiate a correlation of blebbing between cells in contact. Instead of this, we have taken advantage of the fact that we can stimulate a cell to bleb by nudging or stroking it with a micropipette or smoothed glass probe controlled by a micromanipulator.

Eight individual blastula cells were observed in culture for 2 min, during which one of the cells did notbleb while the other seven initiated a new bleb every $30 \mathrm{~s}$. These cells were then nudged. The cell which had not blebbed did not form a bleb when nudged nor during the next minute. Six cells blebbed within $10 \mathrm{~s}$ of being nudged, three of these within $5 \mathrm{~s}$. One of these cells already had a bleb but a new bleb was initiated $10 \mathrm{~s}$ after nudging. The remaining cell also had a bleb but did not initiate a new bleb after nudging when observed for $1 \mathrm{~min}$. The bleb which formed on nudging was always diametrically opposite the point where the cell was touched, or almost so. In no case did the bleb form where the cell was touched.

Touching the cell thus seems to stimulate blebbing. This suggests that the increased number of blebbing deep cells in vivo as development proceeds during the blastula stage ${ }^{b}$ may be due to the increased probability of blebbing cells touching each other. We suggest in addition that this sensitivity to touch in vitro also operates when cells move in streams in vivo, as in the Fundulus germ ring during gastrulation, and that cell movement forward is enhanced by cells bumping into the rear of cells ahead of them. This mechanism would only operate if the cell movement is directional, as in morphogenetic movements. Curtis ${ }^{11}$ has pointed out that such shearing of cells against each other would effect viscosity changes in their surfaces, and in appropriate conditions could promote motility.

Amoebae are also stimulated to produce pseudopodia when prodded with a needle, but in this case the protrusion is formed near the site of stimulation. Goldacre ${ }^{12}$ has suggested that production of a pseudopod is stimulated by the membrane interacting with the endoplasm of the cell. Although in deep cells there is no evidence for sol-gel transformation, the blebs formed may be analogous to the ectoplasm of an amoeba in that cytoplasm seems to flow into a bleb as it elongates to form a longer protrusion.

To test whether the stimulus for blebbing could be transmitted to another cell, nine doublets of blastula cells adherent to the substratum were studied. One of the two cells was chosen at random to be nudged away from the region of contact. In one doublet, neither the cell nudged nor the other blebbed for $30 \mathrm{~s}$ after nudging. In all other doublets both cells blebbed simultaneously; five after $6 \mathrm{~s}$, two after $10 \mathrm{~s}$, and one after $25 \mathrm{~s}$. The blebs formed in the nudged cells in the same position as in single cells. The blebs forming in the attached cells were usually at one side of the region of contact between the cells. This suggests that the surface activity of the cells of the doublet is linked.

As Fundulus deep cells have been shown to be electrically coupled ${ }^{13}$, we suggest that this might be the mechanism whereby surface activities of cells are coordinated. It is clear, however, that contact with another cell also restricts the activity of an individual cell. Blebs do not form at points of contact and it is possible that the cell surface is not free to flow in these regions (our work in preparation). The question is whether surface activity in groups of cells is coordinated by interaction of the membranes themselves or by messages passing through communicating channels between cells. The same question applies to the local effects on ruffling ${ }^{14}$ and contraction ${ }^{15}$ on contact with another cell.

This work was supported by grants from the NSF and NIH.

\section{TICKLE}

Department of Biology as Applied to Medicine,

Middlesex Hospital Medical School,

London WIP $6 D B, U K$, and

Marine Biological Laboratory,

Woods Hole,

\section{J. P. TRINKaUs}

\section{Department of Biology,}

Yale University,

New Haven, Connecticut 06520, and

Marine Biological Laboratory,

Woods Hole, Massachusetts 02543

Received March 22; accepted April 20, 1976.

1 Abercrombie, M., In Vitro, 6, 128-142 (1970)

2 Vogt, W., Arch. Entw. Organ., 120, 384-706 (1929).

3 De Haan, R. L.. Expl Cell Res., 29, 544-560 (1963)

5 Trinkaus, J. P., Cells into Organs (Prentice-Hall, Englewood Cliffs, New Jersey, 1969).

6 Trinkaus, J. P., Devl Biol., 30, 68-103 (1973)

7 Trinkaus, J. P., Devl Biol., 7, 513-532 (1963)

Armstrong, P. B., and Child. J. S., Biol. Bull., 128, 143-154 (1965).

9 Tickle, C. A., and Trinkaus, J. P.. J. Cell Sci., 13, 721-726 (1973).

10 Lucy, E. C. A., and Curtis, A. S. G., Med. Biol. Illust., 9, 86-93 (1959).

11 Curtis, A. S. G., Expl Cell Res. Suppl., 8, 107-122 (1961).

2 Goldacre, R. V.. Symp. Soc, exp. Biol., 6, 128-144 (1952)

13 Bennett, M. V. L.. and Trinkaus. J. P.. J. Cell. Blol., 44, 592-610 (1970)

4 Trinkaus, J. P., Betchaku, T., and Krulikowski, L. S., Expl Cell Res., 64, 291-300 (1971)

s Abercrombie, M., and Dunn, G., Expl Cell Res., 92, 57-62 (1975) 